\title{
Enhanced attention precedes self-initiated locomotion in an electric fish
}

\author{
James J Jun ${ }^{1,2,3^{*}}$, Andre Longtin ${ }^{1,2,3}$, Leonard Maler ${ }^{2,3}$ \\ From The Twenty Third Annual Computational Neuroscience Meeting: CNS*2014 \\ Québec City, Canada. 26-31 July 2014
}

Volition is generally considered as a defining human faculty; but the outcome of a voluntary decision can be predicted by brain activity even before subject's conscious awareness [1], and similar phenomena are observed in many species. Preparatory neural activities for voluntary movements involve movement planning and decision making [2], and active movements accompany heightened attention [3]. We show that enhanced attention precedes self-initiated movements in an animal model that exhibits a readily observable and quantifiable sensory acquisition rate. In addition to demonstrating preparatory increases in sensory sampling, our results reveal close similarities between the sensory sampling and the neural activity suggest associated with voluntary decision making [4].

Cortical activity precedes self-initiated movements by several seconds in mammals; this observation has led into inquiries on the nature of volition [1]. Preparatory neural activity is known to be associated with decision making and movement planning [2]. Self-initiated locomotion has been linked to active sensing indicative of enhanced attention [3]; however, the precise temporal relationship between sensory acquisition and voluntary movement initiation has not been established. Based on long-term monitoring of sensory sampling activity that is readily observable in freely behaving pulse-type electric fish, we show that heightened sensory acquisition precedes spontaneous initiation of swimming. Gymnotus sp. revealed a bimodal distribution of electric organ discharge rate (EODR) demonstrating Down- and Up-states of sensory sampling and neural activity; movements only occurred during Up-states and Up-states were initiated before movement-onset. EODR during voluntary swimming initiation exhibited greater trial-to-trial variability than the

\footnotetext{
* Correspondence: jamesjun@gmail.com

'Department of Physics, University of Ottawa, Ottawa, ON, Canada, K1N 6N5
} Full list of author information is available at the end of the article sound-evoked increases in EODR. The sensory sampling variability increased before, and declined after voluntary movement onset as previously observed for the neural variability associated with decision-making in primates [4]. In contrast, stimulus onset quenched the sampling variability similar to that previously reported in neural variability [5]. Spontaneous movements occurred randomly without a characteristic timescale, and no significant temporal correlation was found between successive movement intervals.

\section{Conclusion}

Using statistical analyses of spontaneous exploratory behaviors and associated preparatory sensory sampling increase, we conclude that electric fish exhibit all the established hallmarks of volition, and that voluntary behaviors in vertebrates may generally be preceded by increased sensory sampling. The dorsal telencephalon is required for spatial learning in teleosts and might initiate movement via its projections to the tectum [6]. Our results therefore suggest that comparative studies of the neural basis of volition may therefore be possible in pulse-type electric fish, given the substantial homologies between the telencephali of electric fish and mammals.

\footnotetext{
Authors' details

'Department of Physics, University of Ottawa, Ottawa, ON, Canada, K1N 6N5. ${ }^{2}$ Department of Cellular and Molecular Medicine, University of Ottawa, Ottawa, ON, Canada, K1H 8M5. ${ }^{3}$ Centre for Neural Dynamics of Physics, University of Ottawa, Ottawa, ON, Canada, K1H 8M5.
}

Published: 21 July 2014
References
1. Libet B, Gleason CA, Wright EW, Pearl DK: Time of conscious intention to act in relation to onset of cerebral activity (readiness-potential): the unconscious initiation of a freely voluntary act. Brain 1983, 106(3):623-642.
2. Haggard P: Human volition: towards a neuroscience of will. Nat Rev Neurosci 2008, 9(12):934-946.

O) Biomed Central (c) 2014 Jun et al; licensee BioMed Central Ltd. This is an Open Access article distributed under the terms of the Creative Commons Attribution License (http://creativecommons.org/licenses/by/4.0), which permits unrestricted use, distribution, and reproduction in any medium, provided the original work is properly cited. The Creative Commons Public Domain Dedication waiver (http:// creativecommons.org/publicdomain/zero/1.0/) applies to the data made available in this article, unless otherwise stated. 
3. Mitchinson B, Prescott TJ: Whisker movements reveal spatial attention: a unified computational model of active sensing control in the rat. PLOS Comp Biol 2013, 9(9):e1003236.

4. Churchland AK, Kiani R, Chaudhuri R, Wang XJ, Pouget A, Shadlen MN: Variance as a signature of neural computations during decision making. Neuron 2011, 69(4):818-831.

5. Churchland MM, Byron MY, Cunningham JP, Sugrue LP, Cohen MR, Corrado GS, Shenoy KV: Stimulus onset quenches neural variability: A widespread cortical phenomenon. Nat Neurosci 2010, 13(3):369-378.

6. Giassi ACC, Duarte TT, Ellis W, Maler L: Organization of the gymnotiform fish pallium in relation to learning and memory: Il. Extrinsic connections. J Comp Neurol 2012, 520(15):3338-3368.

doi:10.1186/1471-2202-15-S1-P104

Cite this article as: Jun et al:: Enhanced attention precedes self-initiated locomotion in an electric fish. BMC Neuroscience 2014 15(Suppl 1):P104.

\section{Submit your next manuscript to BioMed Central} and take full advantage of:

- Convenient online submission

- Thorough peer review

- No space constraints or color figure charges

- Immediate publication on acceptance

- Inclusion in PubMed, CAS, Scopus and Google Scholar

- Research which is freely available for redistribution

Submit your manuscript at www.biomedcentral.com/submit
Ciomed Central 